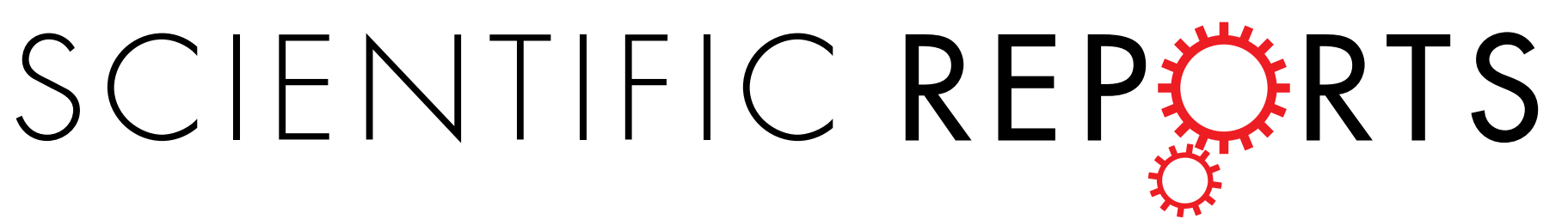

\title{
OPEN Publisher Correction: Discovery of targetable genetic alterations in advanced non-small cell lung cancer using a next-generation sequencing-based circulating tumor DNA assay
}

\author{
Helei Hou ${ }^{1}$, Xiaonan Yang ${ }^{2}$, Jinping Zhang ${ }^{3}$, Zhe Zhang ${ }^{4}$, Xiaomei Xu ${ }^{5}$, Xiaoping Zhang ${ }^{6}$, \\ Chuantao Zhang ${ }^{1}$, Dong Liu ${ }^{1}$, Weihua Yan ${ }^{7}$, Na Zhou ${ }^{1}$, Hongmei Zhu ${ }^{8}$, Zhaoyang Qian ${ }^{8}$, \\ Zhuokun $\mathrm{Li}^{2}$ \& Xiaochun Zhang ${ }^{1}$
}

Correction to: Scientific Reports https://doi.org/10.1038/s41598-017-14962-0, published online 03 November 2017

The original HTML version of this Article contained a typographical error in the publication date '03 November 2017' which was incorrectly given as '06 November 2017'. This has now been corrected in the HTML version of the Article.

(i) Open Access This article is licensed under a Creative Commons Attribution 4.0 International c. License, which permits use, sharing, adaptation, distribution and reproduction in any medium or format, as long as you give appropriate credit to the original author(s) and the source, provide a link to the Creative Commons license, and indicate if changes were made. The images or other third party material in this article are included in the article's Creative Commons license, unless indicated otherwise in a credit line to the material. If material is not included in the article's Creative Commons license and your intended use is not permitted by statutory regulation or exceeds the permitted use, you will need to obtain permission directly from the copyright holder. To view a copy of this license, visit http://creativecommons.org/licenses/by/4.0/.

(C) The Author(s) 2018

\footnotetext{
${ }^{1}$ Department of Medical Oncology, The Affiliated Hospital of Qingdao University, Qingdao University, 16 Jiangsu Road, Qingdao, 266005, China. ${ }^{2}$ BGI-Qingdao Institute, Qingdao SINO-GERMAN Ecopark, 2877 Tuanjie Road, Qingdao, 266555, China. ${ }^{3}$ Department of Experimental Therapeutics, University of Texas, South Campus Research Building 4 (4SCR), Room 4SCR3.2085, 1901 East Road, Houston, Texas, 77054, USA. ${ }^{2}$ Department of Thoracic Surgery, Qingdao Municipal Hospital, 1 Jiaozhou Road, Qingdao, 266011, China. ${ }^{5}$ Department of Medical Oncology, Qingdao Municipal Hospital, 5 Donghai Middle Road, Qingdao, 266071, China. ${ }^{6}$ BGI-Shenzhen, Shenzhen, 518083, China. ${ }^{7}$ Department of Pathology, The Affiliated Hospital of Qingdao University, Qingdao University, 16 Jiangsu Road, Qingdao, 266005, China. ${ }^{8}$ Binhai Genomics Institute, BGI-Tianjin, BGI-Shenzhen, Tianjin, 300308, China. Helei Hou and Xiaonan Yang contributed equally to this work. Correspondence and requests for materials should be addressed toX.Z. (email: zhangxiaochun9670@126.com)
} 